Article

\title{
Active Transport Network Design Based on Transit-Oriented Development and Complete Street Approach: Finding the Potential in Qazvin
}

\author{
Hamid Mirzahossein ${ }^{1, * \mathbb{D}}$, Amir Abbas Rassafi ${ }^{1} \mathbb{D}$, Zahra Jamali ${ }^{1}$, Robert Guzik ${ }^{2} \mathbb{D}^{\mathbb{D}}$, Alessandro Severino ${ }^{3} \mathbb{D}$ \\ and Fabio Arena ${ }^{4}$ iD
}

Citation: Mirzahossein, H.; Rassafi,

A.A.; Jamali, Z.; Guzik, R.; Severino,

A.; Arena, F. Active Transport

Network Design Based on

Transit-Oriented Development and

Complete Street Approach: Finding

the Potential in Qazvin.

Infrastructures 2022, 7, 23. https://

doi.org/10.3390/

infrastructures7020023

Academic Editor: Benedetto Barabino

Received: 13 January 2022

Accepted: 13 February 2022

Published: 16 February 2022

Publisher's Note: MDPI stays neutral with regard to jurisdictional claims in published maps and institutional affiliations.

Copyright: (C) 2022 by the authors. Licensee MDPI, Basel, Switzerland. This article is an open access article distributed under the terms and conditions of the Creative Commons Attribution (CC BY) license (https:// creativecommons.org/licenses/by/ $4.0 /)$.
1 Department of Civil-Transportation Planning, Imam Khomeini International University, Qazvin 34148-96818, Iran; rasafi@eng.ikiu.ac.ir (A.A.R.); zahrajamali15@gmail.com (Z.J.)

2 Institute of Geography and Spatial Management, Jagiellonian University, Gronostajowa 7, 30-387 Krakow, Poland; robert.guzik@uj.edu.pl

3 Department of Civil Engineering and Architecture, University of Catania, 95123 Catania, Italy; alessandro.severino@unict.it

4 Faculty of Engineering and Architecture, Kore University of Enna, Cittadella Universitaria, 94100 Enna, Italy; fabio.arena@unikore.it

* Correspondence: mirzahossein@eng.ikiu.ac.ir

\begin{abstract}
Today, automobile dependency constantly causes traffic congestion, delays, reduced access, increased fuel and energy consumption, and environmental emissions. Automobile dependency has caused many direct and indirect transportation problems that may influence our life. Urban planners and transportation engineers seek to improve transport networks considering social issues. One of the most successful solutions for advocating sustainable transport is transit-oriented development (TOD). Another solution that planners encourage to use is designing the roadways based on a complete street approach, which is a system that provides safe, convenient, and comfortable travel and increases accessibility for users of all ages regardless of their transport modes. The present study employed the saturated roads that have heavy traffic most of the time and public transport e-ticket data to investigate the potential complete streets in Qazvin. An online questionnaire was developed using the Analytic Hierarchy Process (AHP) method based on the TOD and the complete street framework to investigate the essential criteria for redesigning the network based on the active transport approach. Thus, after analyzing the six criteria (density, diversity, distance, accessibility, demand management, and design) and eight sub-criteria (pedestrian flow, pedestrian density, connectivity, safety, bike route, bus route, road width, and urban tree canopy index), the proposed active transport network emerged and results show that five high priority streets were identified to be considered as a solution.
\end{abstract}

Keywords: transit-oriented development (TOD); complete street; active transport; public transport

\section{Introduction}

In addition to automobile dependency, decreasing citizens' physical activity has caused many environmental and transportation problems, such as increasing pollution, reducing the health index, and reducing safety. In fact, pollution is an environmental problem that is caused by inappropriate use of transportation modes especially private cars. In other words, pollution is an indirect result of automobile dependency. Moreover, urban sprawl that relates to automobile dependency is one of the significant transport debates of recent decades. A complete street concept, as a novel solution in transportation planning, provides an alternative mode of travel for all transportation users with any ability in all weather conditions. Complete street design is one of the most popular ways to ensure accessibility, safety, and comfort of transportation users [1]. Recent studies investigate that the choice of travel and transport depends on urban planning. In other words, urban design and planning play an essential role in sustainable transportation [2]. For example, the main 
mode of travel in the Netherlands is bicycles. In this country, all modes of travel can be used. Still, the primary mode of interest for people for inner-city travel is bicycles [3] due to its unique bike-friendly city design and planning. Cars are not removed from the street in a complete street, and all travel modes have balanced. Sustainable or green travel modes, such as walking, which are more acceptable and popular for the complete streets, increase the city's health and vitality index by increasing mobility [4]. In some studies, the complete street's walkability is evaluated based on three criteria: density, diversity, and connectivity [5]. Lack of optimal route for pedestrian traffic on the streets and friction created in pedestrian and car flow leads to increased travel time, accidents, and reduced level of service [6]. According to studies, the ideal distance is $400-800 \mathrm{~m}$ for walking to reach public transport stations and $2.5 \mathrm{~km}$ for leisure or shopping trips [7]. This distance for bicycles can be increased up to $50 \mathrm{~km}$. It takes $0.8-1.5 \mathrm{~km}$ to reach public transport stations, $5-15 \mathrm{~km}$ for business trips, and $15-50 \mathrm{~km}$ for leisure trips [8]. In general, $2.5 \mathrm{~km}$ of bike trip saves $180 \mathrm{~L}$ of gasoline and reduces $450 \mathrm{~kg}$ of carbon dioxide emission, equivalently. Additionally, each car's parking space takes up as much space as 5-10 bicycles [9].

Another available solution that planners use is active transportation, which uses nonmotorized methods such as walking and cycling. Factors affecting active transport are divided into two categories: (1) observable and measurable characteristics and (2) invisible and perceptual characteristics. Studies suggest that measured environmental characteristics affect perceptual characteristics and play a more important role in active transport [10]. In some countries, including Japan, urban planners pay more attention to providing equal access for users, including the elderly and the disabled, due to the Anti-Discrimination Act, the high average age, and the large population. Most streets have traffic restrictions with speed limits for private cars. According to studies, vehicles' speed is directly related to safety. The use of private cars decreases as average vehicles' speed declines, and safety and access increase [3]. Another mode of travel in the complete street is public transport, which always has the highest urban travel demand.

In reviewing the literature in regards to complete street urban planning, eleven criteria are used to identify candidates. These criteria are: (1) bicycle network, (2) bus network, (3) citizen dimension, (4) connectivity, (5) human activity density, (6) pedestrian flow, (7) safety, (8) social and material deprivation, (9) street width, (10) urban planning, and (11) urban tree canopy index [11]. Complete street design has been shown to lead to economic efficiency, environmental sustainability, and social justice in access to sustainable modes of transportation $[4,12]$. In these regards, it can be concluded that the advantages of using a complete street can be divided into six general groups: improving safety, accessibility, level of service (LOS), environmental benefits, economic, and social justice. Figure 1 shows some advantages of using a complete street in urban planning.

Besides a complete street approach, transit-oriented development (TOD) could be considered as another policy to encourage shifting from private car to public transport. TOD is a functional combination of land use and public transport by creating compact neighborhoods' land-use planning close to public transport stations [13]. This type of development brings people, businesses, and services together, and is designed to make trips on foot, bike, public transport, and private cars safe, efficient, and comfortable [14]. The goal of TOD is to make more use of green travel modes, especially walking to the station [15].

TOD can be defined as a planning approach to reduce car use and promote the adoption of green travel modes through a high-density, mixed-use, and environmentally friendly development in areas with a specified walking distance from regional centers [16,17]. Some researchers have examined TOD by access and have concluded that the rate of public use of active and public transport increases with access surging [18]. TOD policies affect population, density, income, and resident orientation. Increasing the number of pedestrians, bicycles, bus stops, commercial areas, and traffic around the station will boost TOD efficiency [19]. 


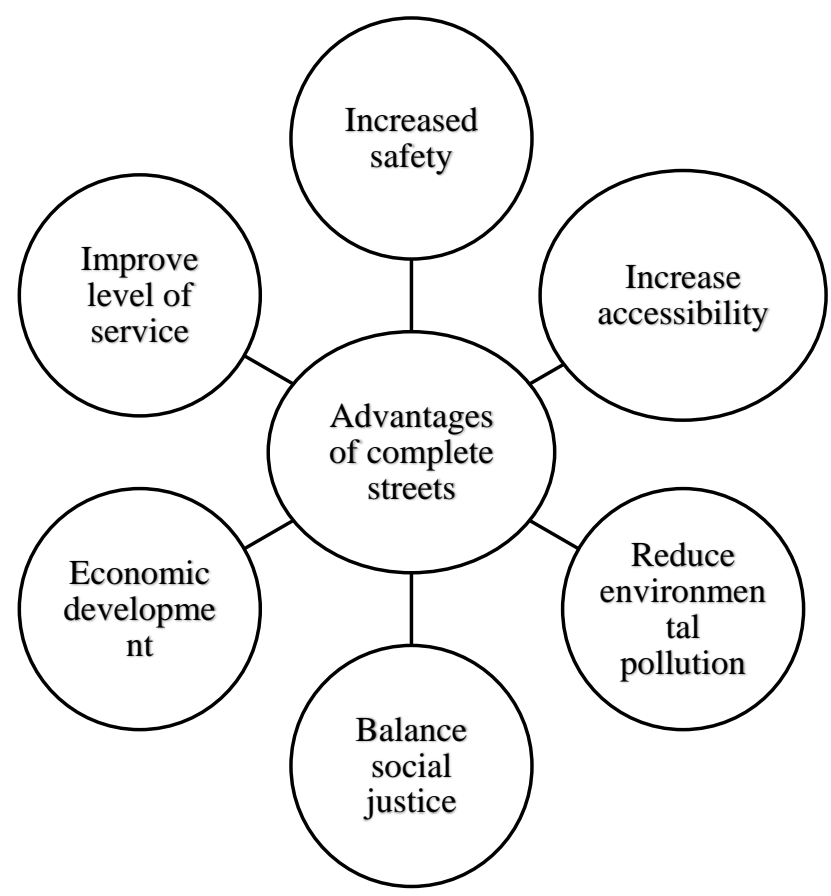

Figure 1. Advantages of using a complete street in urban planning.

The three main criteria for measuring TOD performance are density, diversity, and distance. Depending on the study area, the convenient distance for walking to public transit stations is between 400 and $800 \mathrm{~m}$ on average. This distance will increase 1.7-2.3 times for bicycle mode [7]. In this study, six parameters (6D) [17] are considered to plan and implement TOD. Each is briefly described below.

Density: As noted earlier, reducing the propensity to travel by private car is one of the most important challenges for urban planners. The density index forms the number of housing, households, and job opportunities per square kilometer. Studies suggest that locating stations in high-density areas attracts people to sustainable transportation, including human-centered public transportation, by improving accessibility.

Diversity: One of the factors that can affect a TOD project's success is heterogeneous usage, which is called diversity.

Design: Mixing usages, such as bike paths, sidewalks, and urban tree canopy index, helps create a better environment.

Distance: Distance is a measure of access that effectively determines the quality of public transport services and the amount of investment. The standard distance to the station, measured as the travel time by foot or by bicycle, should effectively attract citizens.

Destination accessibility: The transportation system must provide access to all types of destinations, such as administrative, educational, medical, and service destinations. This aims to boost the efficiency of the transportation system rather than providing closer destinations.

Demand management: Any activity, method, or program that reduces private car travel can increase the use of transportation resources in a more efficient way.

In this study, a combination of redesign policy for complete street and TOD approach is proposed to increase the sustainable or green transportation modes, thus reducing the congestions and energy consumption, and greenhouse gas emissions. This type of development brings people, businesses, and services together and is designed to make trips sustainable on foot, bike, and public transport, and make private cars safe, efficient, and comfortable. Moreover, increasing access is another priority in this approach. Increasing the use of sustainable transport modes (e.g., walking and cycling) is on this project's agenda. Finally, the streets are prioritized to review the design and improvement of passages with a street's human-centered view. In this regard, the combined use of two complete street 
and transit-oriented development approaches is proposed. The Qazvin transportation network has been investigated to identify potential streets to redesign by using the Analytic Hierarchy Process (AHP) method.

\section{Methodology}

In this paper, the AHP method has been used to evaluate streets with potential redesign strategies based on TOD and active transport criteria. AHP is a technique to help multicriteria decision-making. AHP arises ratio scales from paired criteria comparisons and allows for some small inconsistencies in judgments. Inputs can be actual measurements but also subjective opinions. As a result, priorities (weightings) and a consistency ratio will be calculated. AHP is used in a wide range of applications, such as evaluating suppliers, in project management, in the hiring process, or evaluating company performance. A Likert scale assumes that the strength/intensity of an attitude is linear, i.e., on a continuum from strongly agree to disagree strongly, and assumes that attitudes can be measured. Thus, each of the nine responses would have a numerical value to measure the attitude under investigation. In this study, we have used a 9-point Likert scale. Figure 2 shows the steps of the study:

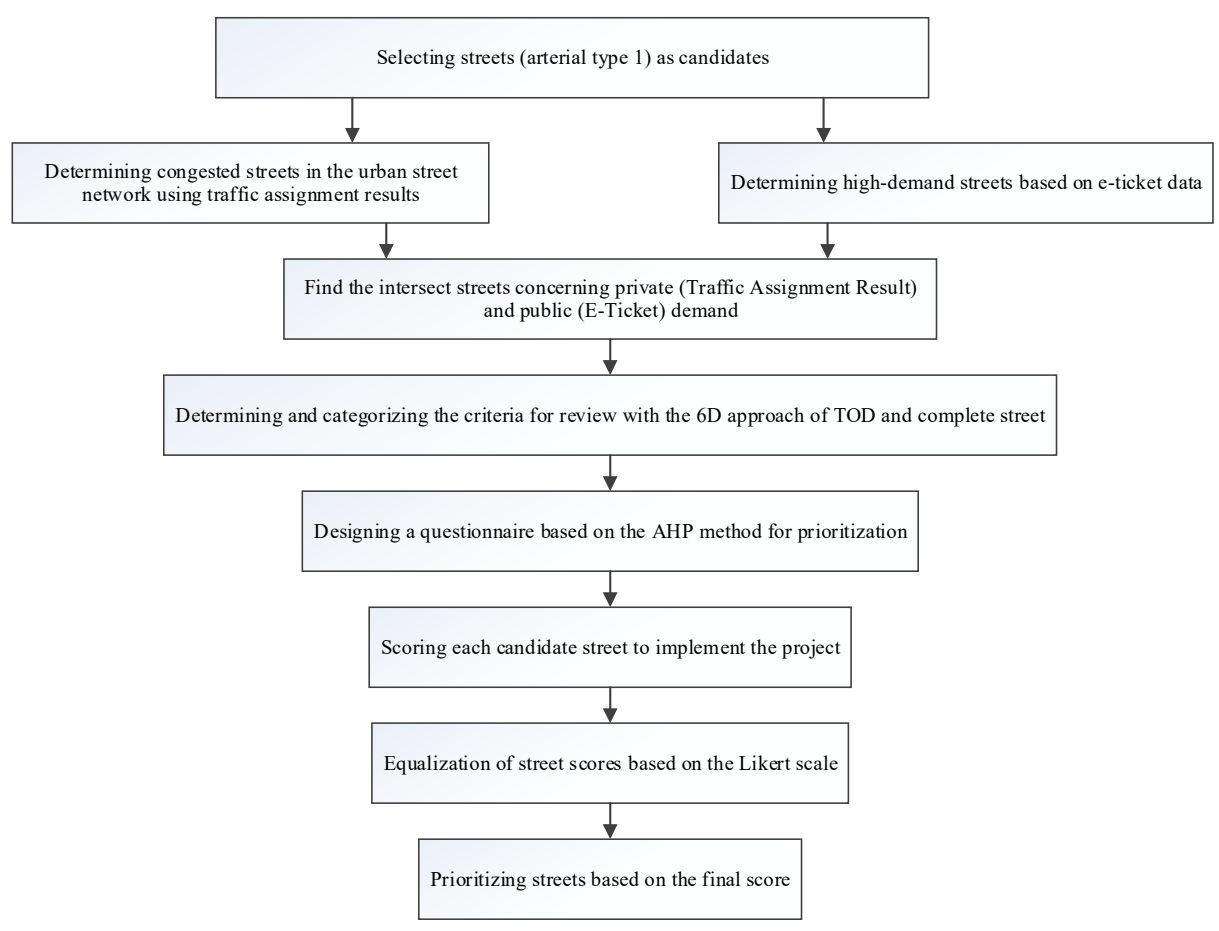

Figure 2. The study steps.

According to Figure 2, the study steps are as follows. These steps are explained more in this section.

Study area: The study area is Qazvin city, the capital of Qazvin province, since it is a candidate for the national pilot of TOD in Iran. It is located $150 \mathrm{~km}$ (93 mi) northwest of Tehran. The area of Qazvin city is about $64.13 \mathrm{~km}^{2}$ and its population in the last census in 2016 is about 600,000 people. Qazvin, an intercity transport network, is designed for travel by bus, taxi, and, to some extent, by bicycle. Tramlines for the city center are on the agenda for implementation in the coming years. Qazvin city has 21 bus lines. The following steps will elaborate on the details of the proposed design approach for Qazvin city.

Step 1: Intersections of the congested streets of Qazvin city and the maximum demand in the bus network are examined based on the data collected from the use of e-tickets. Based on the results of traffic assignment in Qazvin transportation network and from data obtained from the Deputy of Transportation of Qazvin Municipality which was obtained 
from volume capacity ratio, streets named as "Imam Khomeini, Saadi, Ayatollah Taleghani, Molavi, Nasim-e-Shomal, Ayatollah Modarres, Shahid Babaei, Ayatollah Khamenei, Rah Ahan, Asadabadi, Mir Emad, and Shohada Streets" are considered as congested streets in Qazvin city as shown in Figure 3 [20]. This traffic assignment is done as a part of the comprehensive transportation plan of Qazvin city and is run by TransCAD user equilibrium (UE) method.

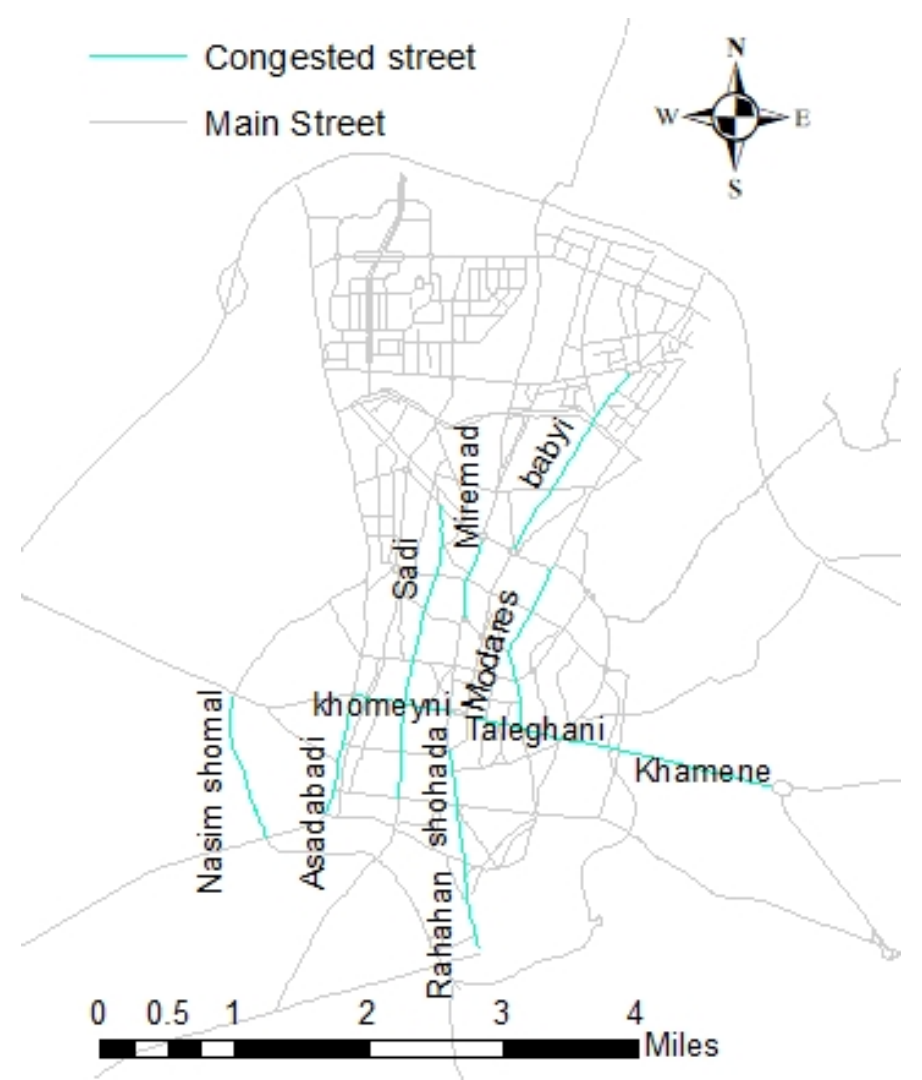

Figure 3. Congested streets in Qazvin.

The Qazvin Bus Transit Organization provides the average daily use of e-tickets for each bus station in Qazvin. Demand matrix using these data and examining the amount of demand in each street shows that Imam Khomeini International University Blvd. and Imam Khomeini, Mir Emad, and Ayatollah Taleghani streets are the most in terms of demand among the city streets, and that Bazaar Terminal, International University, and Minoders town are the most in terms of demand among terminals. According to e-ticket data, high-demand streets are Saadi, Modarres, Naderi, Shohada, Rah Ahan, Imam Khomeini, Ayatollah Taleghani, Mir Emad, Babaei, and part of Beheshti and Ayatollah Khamenei Boulevards, as shown in Figure 4.

To study the intersection of public transport demand and traffic assignment, streets such as Imam Khomeini International University Blvd. with the highest demand for the use of e-tickets in Qazvin are not examined. According to the congested streets in Qazvin, which are obtained from traffic assignment results in the Qazvin street network, obtained from Frankfort method with Transcad Table 1, this shows the prioritization of streets based on the amount of demand allocated from e-ticket data. Nasim-e-Shomal and Molavi streets do not have a bus line. Studies show fare evasion is an important issue in using public transportation demand, especially in e-ticketed data. So according to the Qazvin Bus Transit Organization an average of $15 \%$ evasion is considered [21]. 


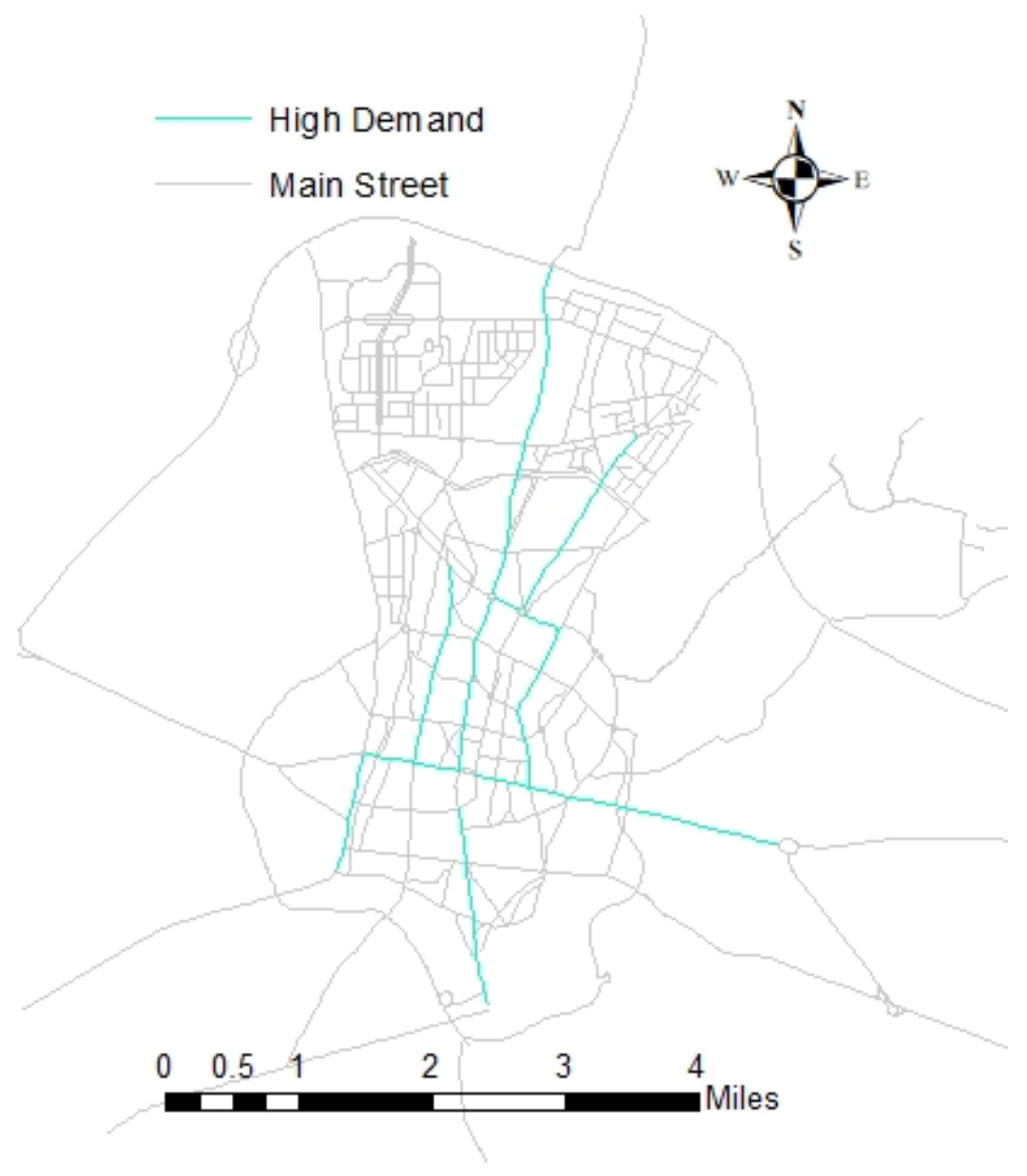

Figure 4. High-demand streets in Qazvin.

Table 1. Demand for public transport on congested streets based on e-tickets.

\begin{tabular}{cc}
\hline Street & Demands Based on E-Tickets Per Day \\
\hline Imam Khomeini & 2391 \\
Mir Emad & 2042 \\
Ayatollah Taleghani & 1543 \\
Saadi & 1123 \\
Ayatollah Khamenei & 970 \\
Shahid Babaei & 733 \\
Rah Ahan & 350 \\
Shohada & 106 \\
Asadabadi & 76 \\
Modarres Ayatollah & 19 \\
Nasim-e-Shomal & - \\
Molavi & - \\
\hline
\end{tabular}

Step 2: Surveys show that Babaei, Modarres, Ayatollah Taleghani, Khamenei, Khomeini, Shohada, and Rah Ahan streets are the intersection of surveys and analyses based on traffic assignment. These selected streets can be seen in Figure 5. 


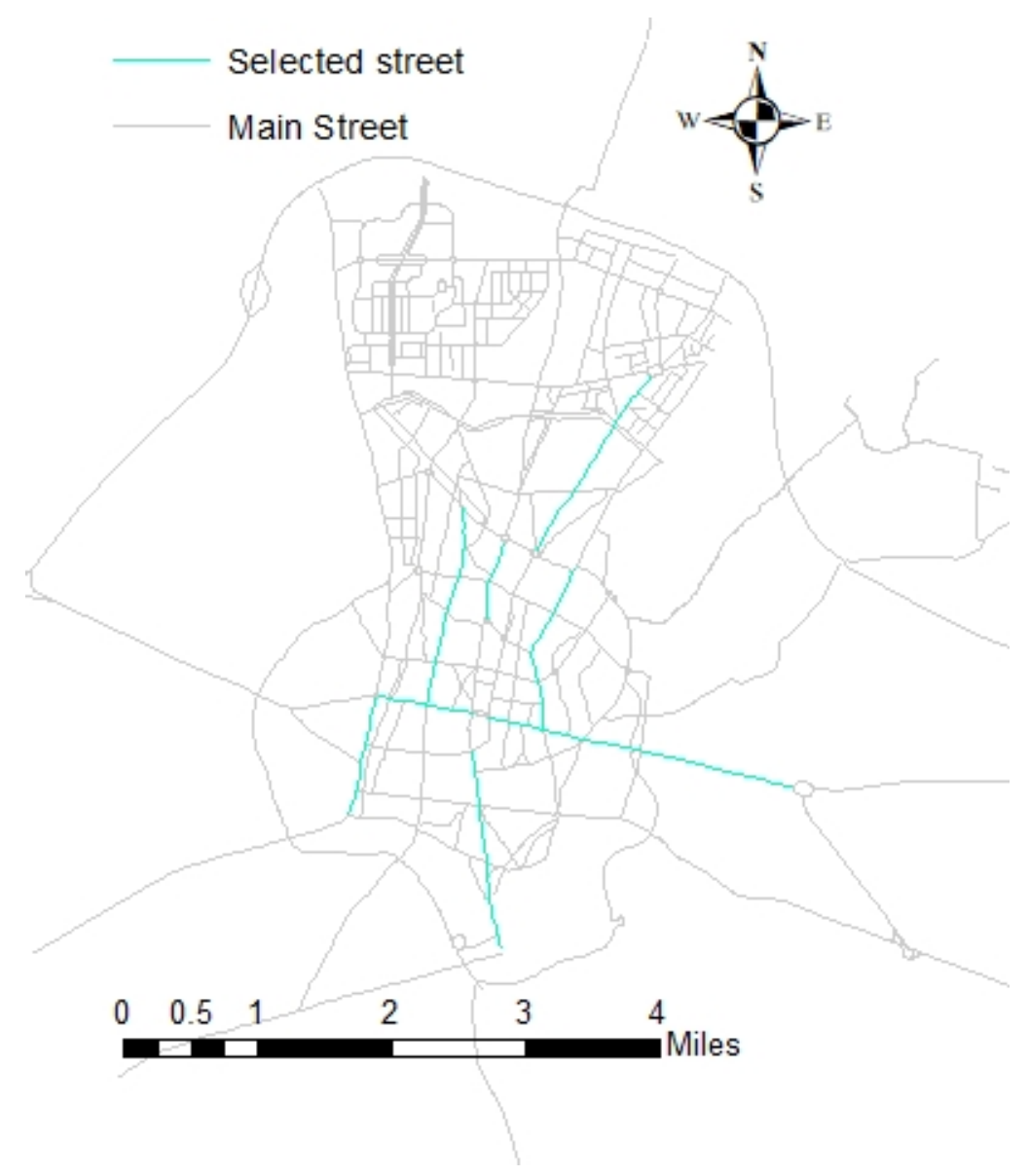

Figure 5. Selected streets for studies in Qazvin.

Step 3: At least three criteria of density, diversity, and distance are important for implementing TOD policy. Moreover, based on the studies in the field of TOD, this study outlines $6 \mathrm{D}$ as the six criteria of density, diversity, distance, demand management, destination access, and design. Moreover, 8 criteria are defined as candidate parameters in complete street. Thus, by intersecting these criteria and emerging the relation, 11 criteria are examined to evaluate street design's potential with a complete street approach which are shown in Figure 6. Each TOD policy is reviewed separately and incrementally to implement the integrated TOD policy and redesign with a complete street approach. Thus, the criteria for the implementation of this integrated project are as follows: 


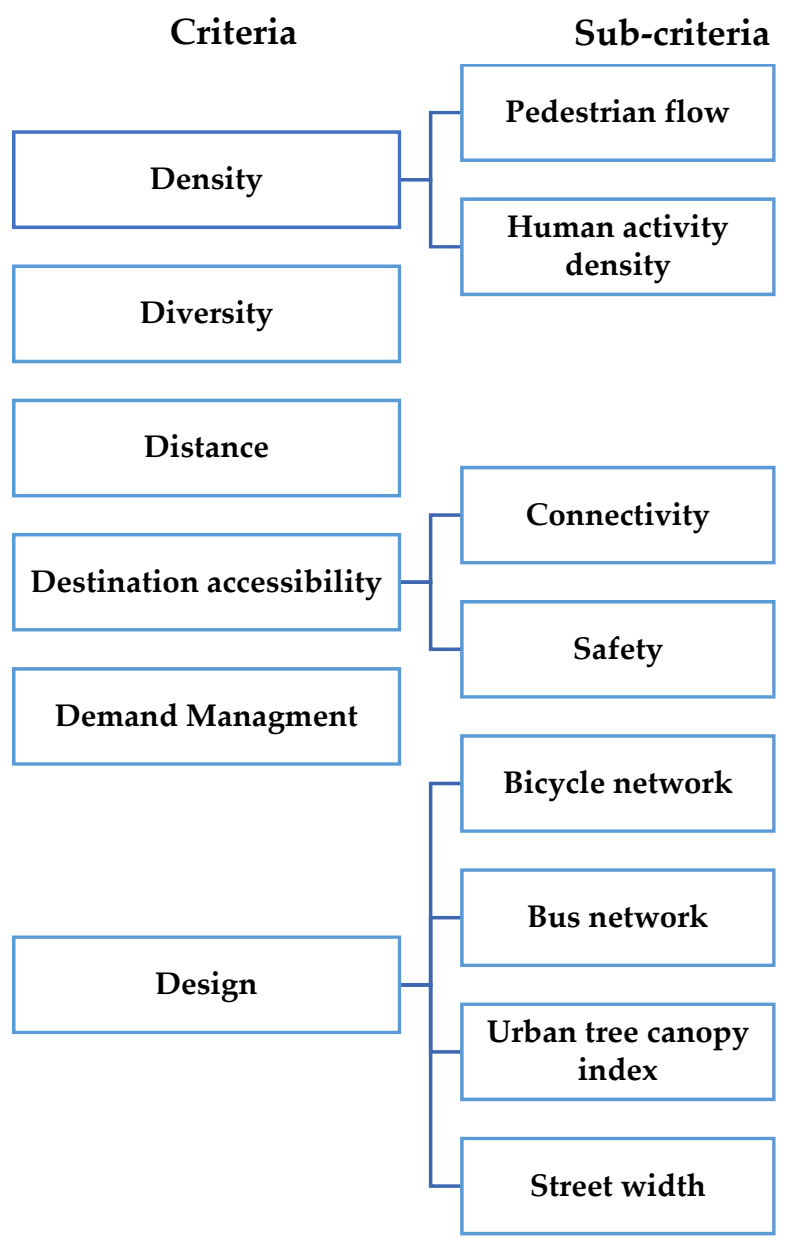

Figure 6. Selected criteria and sub-criteria for evaluation.

Step 4: At this step, a questionnaire was designed using the AHP method and the AHP Inputs survey on https://bpmsg.com/ahp (Accessed on 23 January 2022) [22], and the opinions of 15 professors, specialists, and experts working in the field of public transport in Qazvin were collected.

Step 5: The criteria in each street were calculated.

- The criterion of diversity in each street is calculated based on the area of each use and using the Equation (1):

$$
\text { Entropy formula }=\frac{\sum\left(A_{i j} \ln A_{i j}\right)}{\ln N_{j}}
$$

$A_{i j}=$ the ratio of the area of each land use to the total.

$N_{j}=$ number of land use.

- The distance is obtained by dividing each street's length by the average ideal distance for active transport modes.

- All streets were given the same score for the demand management criterion because the streets studied for improvement or development are not in the design priority of the Qazvin transport network.

- The density of human activity is calculated based on the amount of bus network usage.

- Pedestrian flow and the bicycle network are directly taken from field studies.

- The percentage of urban tree canopy index within a radius of $300 \mathrm{~m}$ of each street is calculated using ArcGIS software.

- The width of streets is extracted using Google Earth data. 
- Each street's connectivity is examined based on the number of candidate streets for the redesign connected to the street's beginning, end, or body to the whole connected streets.

- Safety on each street is obtained by dividing the number of pedestrian and bicycle accidents by the total number of accidents on candidate streets.

Step 6: A 9-point Likert scale is used to equalize street scores to facilitate decisionmaking. Thus, the number 9 indicates the highest score, and the number 1 indicates the lowest score.

Step 7: Based on the analysis and scoring of the selected streets, Taleghani, Imam, Babaei, Saadi, and Modarres Streets obtained the highest scores, respectively, and were introduced as candidates for redesign with the proposed approach.

\section{Discussion}

The following table (Table 2) presents the results of a survey analysis of experts using a questionnaire designed based on the AHP method.

Table 2. The average percentage of importance of the studied criteria based on the survey.

\begin{tabular}{cc}
\hline Selected Criteria & The Average Percentage of Importance \\
\hline Diversity & 11.4 \\
Distance & 14 \\
Demand management & 14.5 \\
Human activity density & 9.9 \\
Pedestrian flow & 4.9 \\
Bicycle network & 2.1 \\
Bus network & 8.7 \\
Urban tree canopy index & 3 \\
Street width & 4.4 \\
Connectivity & 8.7 \\
Safety & 19.2 \\
\hline
\end{tabular}

Table 3 shows the numbers obtained from the calculations.

Table 3. The results of a survey of experts.

\begin{tabular}{|c|c|c|c|c|c|c|c|c|c|c|c|}
\hline Street & 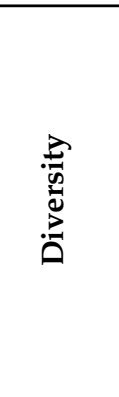 & 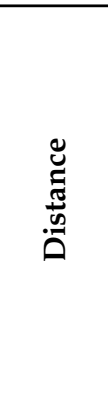 & 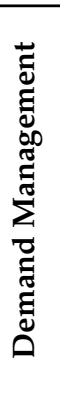 & 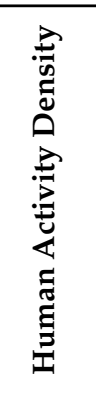 & 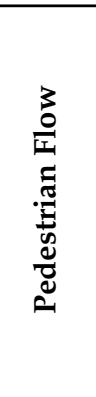 & 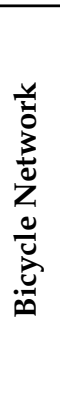 & 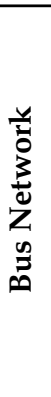 & 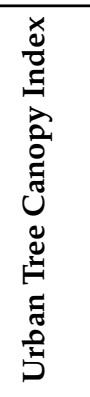 & 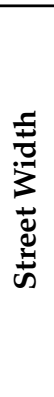 & 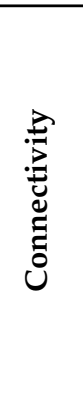 & 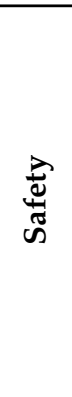 \\
\hline Asadabadi & 87.17 & 82.13 & 0 & 0.82 & 1.2 & 0 & 1 & 17.72 & 0 & 1.14 & 0.96 \\
\hline Babaei & 146.22 & 47.44 & 0 & 7.83 & 14.9 & 0 & 1 & 24.27 & 1 & 1 & 0.94 \\
\hline Khamenei & 106.4 & 46.01 & 0 & 10.37 & 1.72 & 0 & 1 & 27.48 & 0 & 1.14 & 0.89 \\
\hline Imam Khomeini & 104.06 & 103.92 & 0 & 25.55 & 23.62 & 0 & 1 & 8.9 & 1 & 1.5 & 0.78 \\
\hline Mir Emad & 277.94 & 126.58 & 0 & 21.82 & 1.1 & 0 & 1 & 25.22 & 0 & 0 & 0.75 \\
\hline Modarres & 133.49 & 75.09 & 0 & 0.2 & 1.2 & 0.5 & 1 & 33.08 & 0 & 0.25 & 0.88 \\
\hline Rah Ahan & 141.05 & 69.08 & 0 & 3.74 & 14.39 & 0 & 1 & 0.1 & 0 & 1.14 & 0.88 \\
\hline
\end{tabular}


Table 3. Cont.

\begin{tabular}{|c|c|c|c|c|c|c|c|c|c|c|c|}
\hline Street & $\begin{array}{l}\stackrel{\overrightarrow{0}}{0} \\
\stackrel{D}{0} \\
\stackrel{D}{0}\end{array}$ & $\begin{array}{l}\stackrel{\Xi}{\Xi} \\
\stackrel{\tilde{J}}{0} \\
\ddot{0}\end{array}$ & 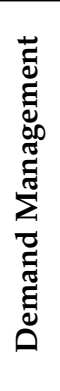 & 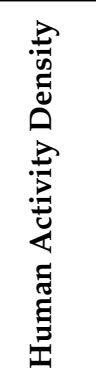 & 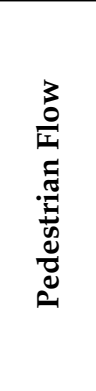 & 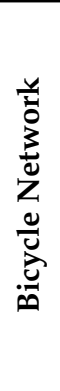 & 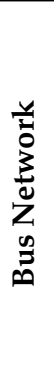 & 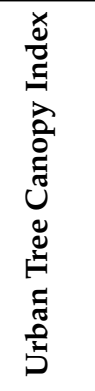 & 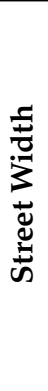 & 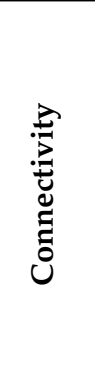 & 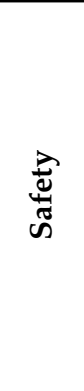 \\
\hline Saadi & 137.83 & 48.82 & 0 & 12 & 7.02 & 0 & 1 & 1.97 & 1 & 1.428 & 0.96 \\
\hline Shohada & 136.6 & 175.18 & 0 & 1.14 & 13.63 & 0 & 1 & 16.51 & 0 & 1.2 & 0.625 \\
\hline Taleghani & 128.67 & 174.4 & 0 & 16.49 & 20.99 & 0.5 & 1 & 12.41 & 1 & 1.33 & 0.7 \\
\hline
\end{tabular}

In the following, the score obtained from the survey of experts is multiplied by the number of each criterion for each street separately, and the results are presented in Table 4.

Table 4. The final weight for each street.

\begin{tabular}{|c|c|c|c|c|c|c|c|c|c|c|c|}
\hline $\begin{array}{l}\text { Criterion Weight * } \\
\text { Criterion }\end{array}$ & $\begin{array}{l}\stackrel{\vec{D}}{0} \\
\stackrel{0}{0} \\
\stackrel{0}{0}\end{array}$ & 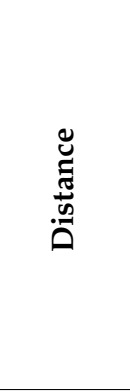 & 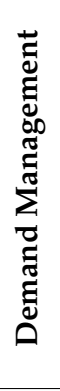 & 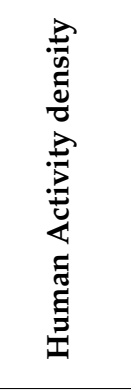 & 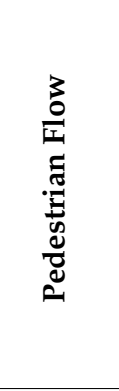 & 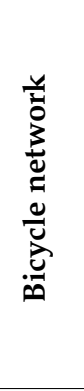 & 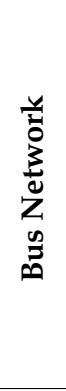 & 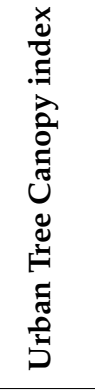 & 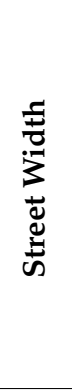 & 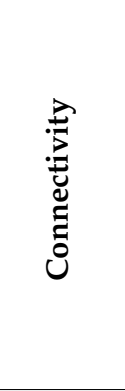 & 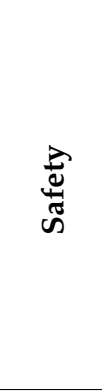 \\
\hline Asadabadi & 431.634 & 1149.82 & 0 & 7.462 & 5.88 & 0 & 8.7 & 53.16 & 0 & 9.918 & 18.432 \\
\hline Babaei & 723.9 & 664.16 & 0 & 71.253 & 73.01 & 0 & 8.7 & 72.81 & 4.4 & 8.7 & 18.048 \\
\hline Khamenei & 526.794 & 644.14 & 0 & 94.367 & 8.637 & 0 & 8.7 & 82.44 & 0 & 9.918 & 17.088 \\
\hline Imam Khomeini & 515.616 & 1454.88 & 0 & 233.505 & 115.738 & 0 & 8.7 & 26.7 & 4.4 & 13.05 & 14.976 \\
\hline Mir Emad & 602.034 & 1772.12 & 0 & 198.562 & 5.39 & 0 & 8.7 & 75.66 & 0 & 0 & 14.4 \\
\hline Modarres & 660.972 & 799.26 & 0 & 1.82 & 5.88 & 1.05 & 8.7 & 99.24 & 0 & 2.175 & 16.896 \\
\hline Rah Ahan & 698.25 & 967.12 & 0 & 34.034 & 70.511 & 0 & 8.7 & 0.3 & 0 & 9.918 & 16.896 \\
\hline Saadi & 682.404 & 683.48 & 0 & 109.2 & 34.398 & 0 & 8.7 & 5.91 & 4.4 & 12.4236 & 18.432 \\
\hline Shohada & 676.248 & 2452.52 & 0 & 10.374 & 66.787 & 0 & 8.7 & 49.53 & 0 & 10.44 & 12 \\
\hline Taleghani & 637.032 & 2441.6 & 0 & 150.059 & 102.851 & 1.05 & 8.7 & 37.23 & 4.4 & 11.571 & 13.44 \\
\hline
\end{tabular}

The results of using this scale can be seen in Table 5 . 
Table 5. The final score of each street.

\begin{tabular}{|c|c|c|c|c|c|c|c|c|c|c|c|c|}
\hline Street & 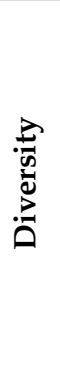 & 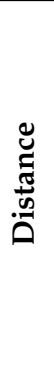 & 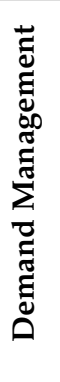 & 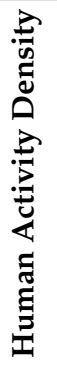 & 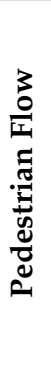 & 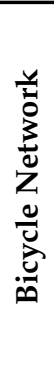 & 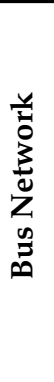 & 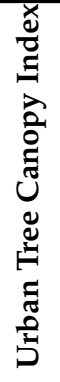 & 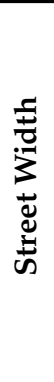 & 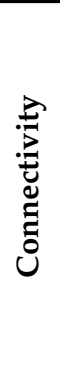 & 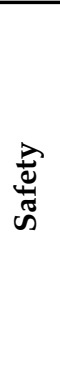 & Total \\
\hline Asadabadi & 1 & 6 & 1 & 1 & 2 & 1 & 1 & 6 & 1 & 4 & 9 & 33 \\
\hline Babaei & 9 & 2 & 1 & 4 & 7 & 1 & 1 & 7 & 9 & 3 & 7 & 51 \\
\hline Khamenei & 3 & 1 & 1 & 5 & 3 & 1 & 1 & 8 & 1 & 4 & 6 & 34 \\
\hline Imam Khomeini & 2 & 7 & 1 & 9 & 9 & 1 & 1 & 3 & 9 & 9 & 4 & 55 \\
\hline Mir Emad & 4 & 8 & 1 & 8 & 1 & 1 & 1 & 7 & 1 & 1 & 3 & 36 \\
\hline Modarres & 6 & 4 & 1 & 1 & 2 & 9 & 1 & 9 & 1 & 2 & 5 & 41 \\
\hline Rah Ahan & 8 & 5 & 1 & 3 & 6 & 1 & 1 & 1 & 1 & 5 & 5 & 37 \\
\hline Saadi & 7 & 3 & 1 & 6 & 4 & 1 & 1 & 2 & 9 & 8 & 8 & 50 \\
\hline Shohada & 7 & 9 & 1 & 2 & 5 & 1 & 1 & 5 & 1 & 6 & 1 & 39 \\
\hline Taleghani & 5 & 9 & 1 & 7 & 8 & 9 & 1 & 4 & 9 & 7 & 2 & 62 \\
\hline
\end{tabular}

The prioritization of the studied streets is according to Table 6 and Figure 7.

Table 6. The prioritization of streets based on scores.

\begin{tabular}{ccc}
\hline Priority & Street & Score \\
\hline 1 & Taleghani & 62 \\
\hline 2 & Imam Khomeini & 55 \\
\hline 3 & Babaei & 51 \\
\hline 4 & Saadi & 50 \\
\hline 5 & Modarres & 41 \\
\hline 6 & Shohada & 39 \\
\hline 7 & Rah Ahan & 37 \\
\hline 8 & Mir Emad & 36 \\
\hline 9 & Ayatollah Khamenei & 34 \\
\hline 10 & Asadabadi & 33 \\
\hline
\end{tabular}

Previous studies show that combining TOD and street redesign perspectives with a complete street approach increases safety, improves access, and improves the quality of transport network services. This leads citizens to opt for green transport modes instead of using private cars. In this regard, the implementation of supportive urban planning policies can be a stimulus for users to adopt active transport or public transport. 


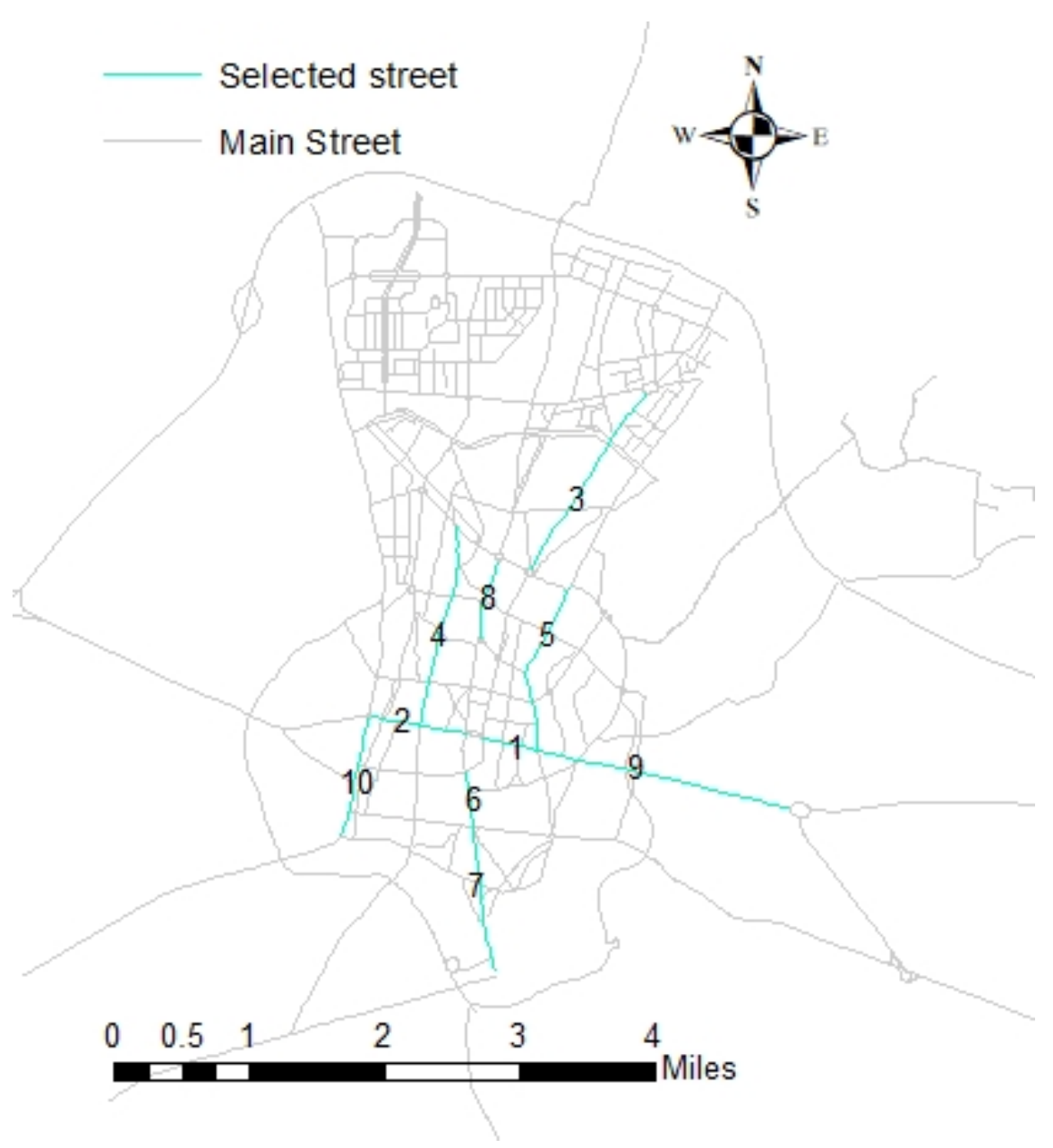

Figure 7. Prioritization of streets in Qazvin.

This is the first case study on the city of Qazvin in which streets are examined based on a combination of TOD and redesign policies with a complete street approach. The study's purpose is not only to design a complete street but to prioritize streets to review the design and improvement of streets with a human-centered view. The generalities examined in this study are shown in Figure 8.

Despite the lowest level of safety among the candidate streets, Mir Emad Street did not receive the necessary scores for a redesign. Moreover, despite the highest demand for public transport, Norouzian Street was not surveyed. Therefore, about $9 \mathrm{~km}$ of the Qazvin street network (5 streets) were selected for redesign with the studied approach.

Due to the streets' layout and the lack of connection between Shahid Babaei Street and other streets, it is suggested that a part of Shahid Beheshti Blvd. between Modares and Saadi Streets (Figure 9) be considered in the improvement project. 


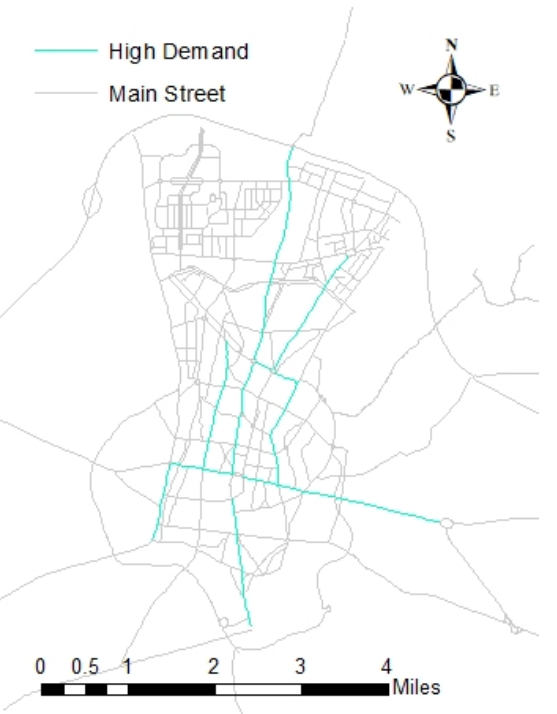

(1)

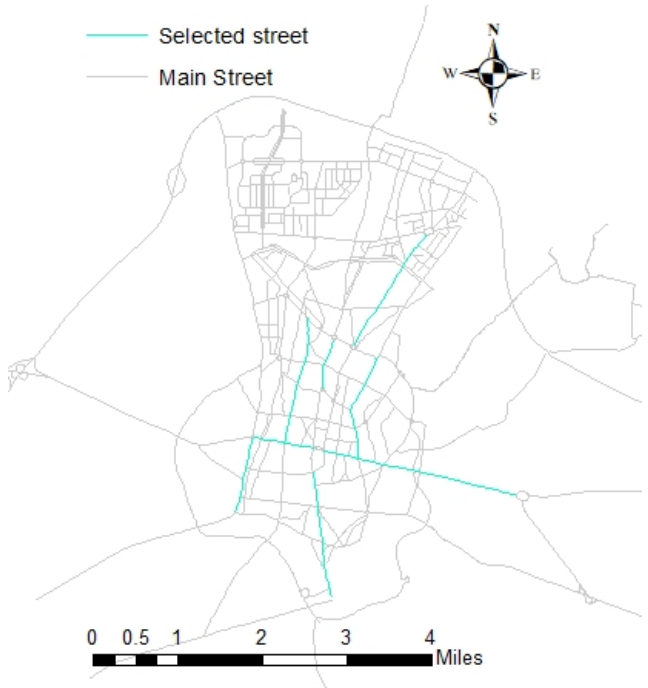

(3)

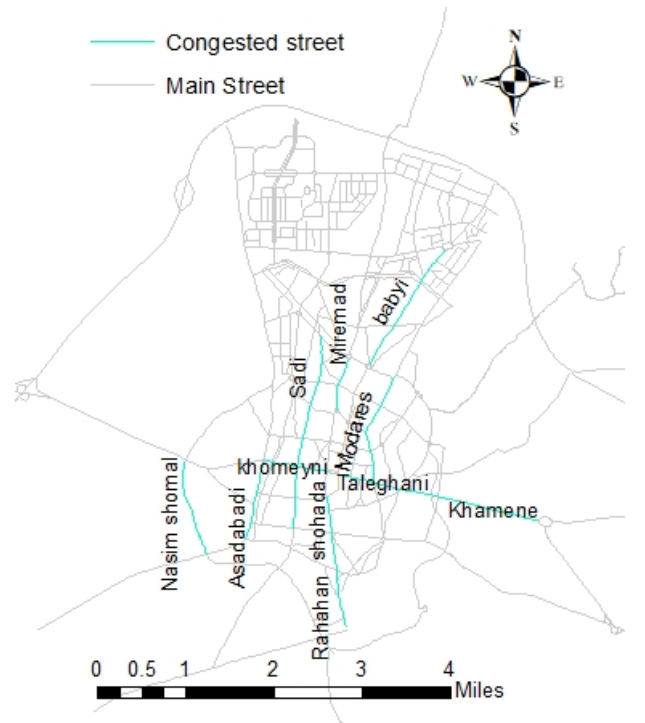

(2)

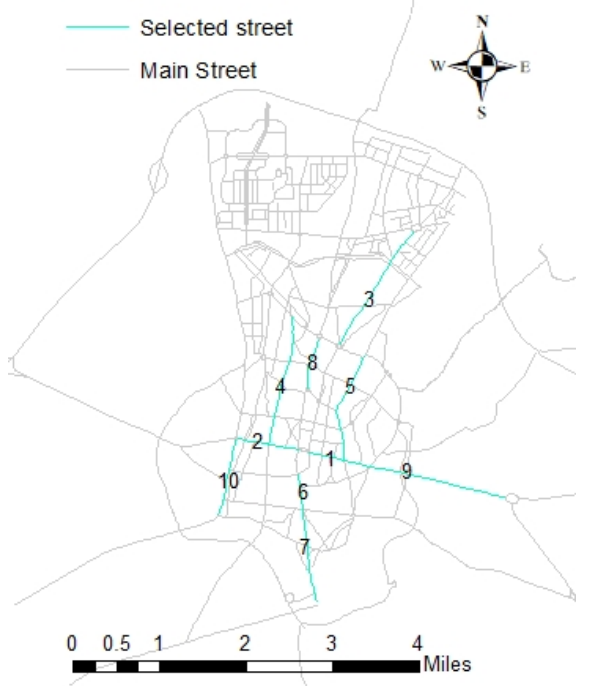

(4)

Figure 8. (1) High-demand streets based on e-ticket data; (2) Congested streets based on traffic assignment; (3) Intersection of congested streets and high-demand streets, and (4) Rank of selected streets for redesign. 


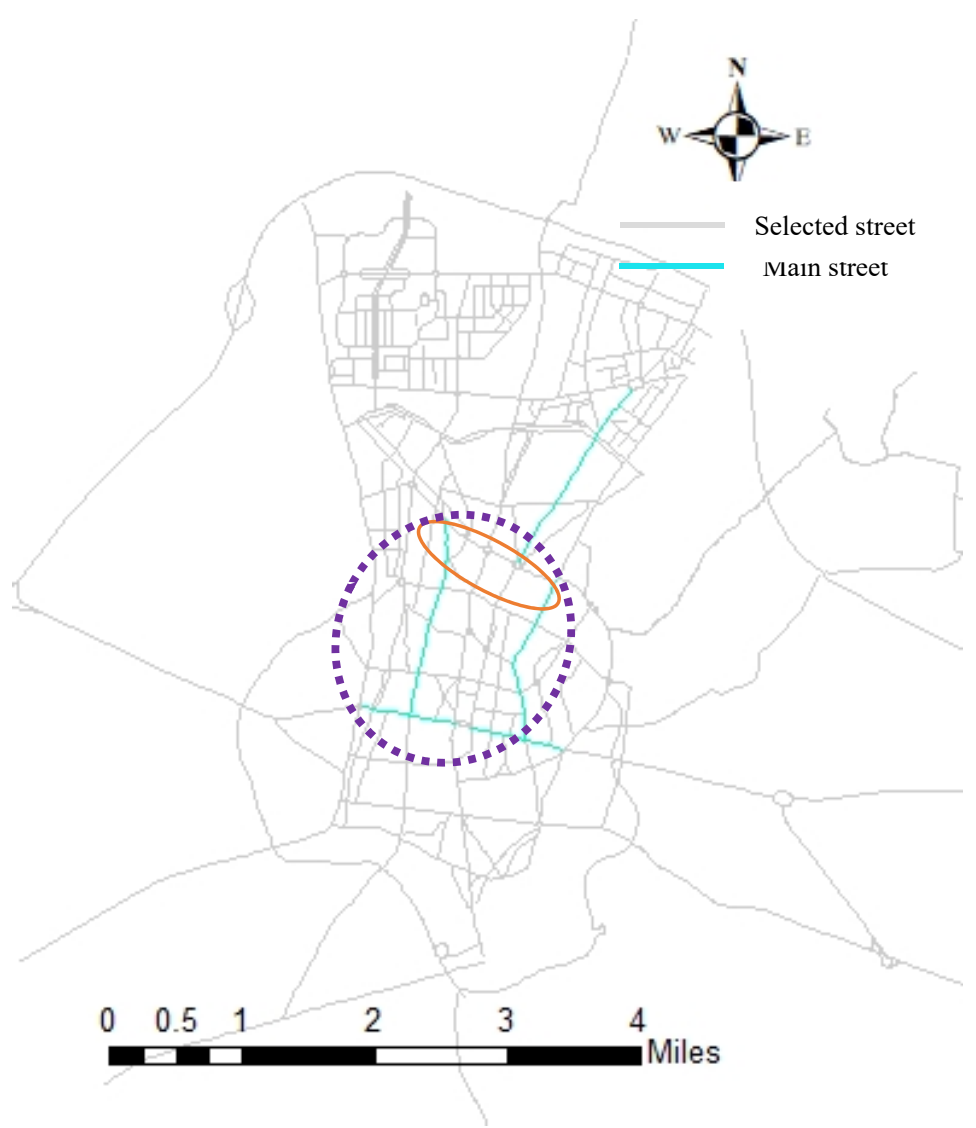

Figure 9. The suggested section (orange ellipse) and complete street ring (dashed violet circle).

\section{Conclusions}

The results indicate that demand management is the second criterion based on importance from transportation experts' perspective. By optimizing each mode of transportation route based on active transport criteria, the demand for travel on these streets can be directed towards a balanced division between modes to manage demand. This can be done by considering the following points:

1. The most imperative point is the human-centered approach of the proposed streets and prioritizing vulnerable users' needs for safety and comfort.

2. Expanding the biking network on proposed streets. Although the Urban Transportation Management Organization (UTMO) in Qazvin has presented a plan to develop a bicycle network in streets, a dedicated bicycle path (as a one-way lane) has been implemented only on Shohada, Modares, and Taleghani streets. As this route is one-way, it will reduce the safety of pedestrians and cyclists.

3. One of the factors affecting the use of public transport that was mentioned in previous chapters is travel time. The public transport network can be improved by reducing the frequency (the interval between the arrivals of two buses to a specific station) and reducing the waiting time at stations.

4. Another effective factor in this field is access to different modes of transportation. It is expected that the use of on-foot mode will increase with the allocation of land with parking use near the complete street, and the use of bicycles will increase with the construction of bike stations. Thus, the demand for these two modes of travel will increase.

5. This paper outlined the possibilities of making complete streets by considering TOD areas and combining them as a ring for increasing accessibility, which is the key point of sustainable transport and could be considered a bridge of transport and land use. Moreover, as a suggestion, part of the required costs for implementing the proposed 
network design could be covered by policies such as parking tolls, passing tolls, and taxes on generator land use (residential, commercial, educational, and administrative) which will increase the accessibility and utilities in the proposed complete street ring.

\begin{abstract}
Author Contributions: Conceptualization, H.M., A.A.R., and R.G.; methodology, H.M., Z.J., and A.A.R.; software, H.M., Z.J., and A.S.; validation, Z.J. and F.A.; formal analysis, H.M. and Z.J.; resources, H.M.; data curation, Z.J., and A.A.R.; writing-original draft preparation, H.M., Zahra Jamali, and R.G.; writing - review and editing, A.S., and F.A. All authors have read and agreed to the published version of the manuscript.
\end{abstract}

Funding: This research received no external funding.

Institutional Review Board Statement: Not applicable.

Informed Consent Statement: Not applicable.

Data Availability Statement: The datasets generated during and/or analysed during the current study are available from the corresponding author on reasonable request.

Conflicts of Interest: The authors declare no conflict of interest.

\title{
References
}

1. Mofolasayo, A. Complete Street concept, and ensuring safety of vulnerable road users. Transp. Res. Procedia 2020, 48, 1142-1165. [CrossRef]

2. Su, S.; Zhang, H.; Wang, M.; Weng, M.; Kang, M. Transit-oriented development (TOD) typologies around metro station areas in urban China: A comparative analysis of five typical megacities for planning implications. J. Transp. Geogr. 2021, 90, 102939. [CrossRef]

3. Calloway, D.M.; Faghri, A. Complete Streets and Implementation in Small Towns. Curr. Urban Stud. 2020, 8, 484-508. [CrossRef]

4. Rode, P.; Floater, G.; Thomopoulos, N.; Docherty, J.; Schwinger, P.; Mahendra, A.; Fang, W. Accessibility in cities: Transport and urban form. In Disrupting Mobility; Springer: Cambridge, MA, USA, 2017; pp. 239-273.

5. Jensen, W.A.; Brown, B.B.; Smith, K.R.; Brewer, S.C.; Amburgey, J.W.; McIff, B. Active transportation on a complete street: Perceived and audited walkability correlates. Int. J. Environ. Res. Public Health 2017, 14, 1014. [CrossRef] [PubMed]

6. Dhanani, A.; Tarkhanyan, L.; Vaughan, L. Estimating pedestrian demand for active transport evaluation and planning. Transp. Res. Part A Policy Pract. 2017, 103, 54-69. [CrossRef]

7. Zuo, T.; Wei, H.; Rohne, A. Determining transit service coverage by non-motorized accessibility to transit: Case study of applying GPS data in Cincinnati metropolitan area. J. Transp. Geogr. 2018, 67, 1-11. [CrossRef]

8. Nemov, P.; Novik, A. Cycling development in Moscow as part of the policy of sustainable development of the metropolis. In IOP Conference Series: Materials Science and Engineering; IOP Publishing: Bristol, UK, 2020.

9. Jones, R.; Kidd, B.; Wild, K.; Woodward, A. Cycling amongst Māori: Patterns, influences and opportunities. N. Z. Geogr. 2020, 76, 182-193. [CrossRef]

10. Arbab, P.; Martinez, J.; Amer, S.; Pfeffer, K. Toward Active Transport as a Utilitarian and Recreational Form of Sustainable Urban Mobility. In Advances in Mobility-as-a-Service Systi; Springer: Berlin/Heidelberg, Germany, 2020.

11. Donaisa, F.M.; Abi-Zeidb, I.; Waygooda, E.O.D.; Lavoiea, R. Assessing and ranking the potential of a street to be redesigned as a Complete Street: A multi-criteria decision aiding approach. Transp. Res. Part A 2018, 124, 1-19.

12. Yua, C.-Y.; Xu, M.; Sara Iman, T. Assessing the economic benefits and resilience of complete streets in Orlando, FL: A natural experimental design approach. J. Transp. Health 2017, 8, 169-178. [CrossRef]

13. Pezeshknejad, P.; Monajem, S.; Mozafari, H. Evaluating sustainability and land use integration of BRT stations via extended node place model, an application on BRT stations of Tehran. J. Transp. Geogr. 2020, 82, 102626. [CrossRef]

14. Barbour, E.; Grover, S.; Lamoureaux, Y.; Chaudhary, G.; Handy, S. Planning and Policymaking for Transit-Oriented Development, Transit, and Active Transport in California Cities. Natl. Cent. Sustain. Transp. 2020. [CrossRef]

15. Pongprasert, P.; Kubota, H. TOD residents' attitudes toward walking to transit station: A case study of transit-oriented developments (TODs) in Bangkok, Thailand. J. Mod. Transp. 2019, 27, 39-51. [CrossRef]

16. Desgeorges, M.M.; Nazare, J.-A.; Enaux, C.; Oppert, J.-M.; Menai, M.; Charreire, H.; Salze, P.; Weber, C.; Hercberg, S.; Roda, C. Perceptions of the environment moderate the effects of objectively-measured built environment attributes on active transport. An ACTI-Cités study. J. Transp. Health 2021, 20, 100972. [CrossRef]

17. Ogra, A.; Ndebele, R. The role of 6Ds: Density, diversity, design, destination, distance, and demand management in transit oriented development (TOD). In Proceedings of the Neo-International Conference on Habitable Environments, San Diego, CA, USA, 19-22 October; 2014; pp. 539-546.

18. Zhang, Y.; Marshall, S.; Manley, E. Network criticality and the node-place-design model: Classifying metro station areas in Greater London. J. Transp. Geogr. 2019, 79, 102485. [CrossRef] 
19. Tamakloe, R.; Hong, J.; Tak, J. Determinants of transit-oriented development efficiency focusing on an integrated subway, bus and shared-bicycle system: Application of Simar-Wilson's two-stage approach. Cities 2021, 108, 102988. [CrossRef]

20. Municipality, Qazvin Department of Traffic and Transportation. Studies of the Comprehensive Plan of Transportation and Traffic of Qazvin Urban Complex; Municipality, Qazvin Department of Traffic and Transportation: Qazvin, Iran, 2013.

21. Barabino, B.; Lai, C.; Olivo, A. Fare evasion in public transport systems: A review of the literature. Public Transp. 2020, 12, 27-88. [CrossRef]

22. Goepel, K.D. Implementation of an Online Software Tool for the Analytic Hierarchy Process (AHP-OS). 2018. Available online: https:/ /ijahp.org/index.php/IJAHP/article/view/590 (accessed on 1 February 2022). 